\title{
Synthesis and Characterization of Heterostructure $\mathrm{Pd} / \mathrm{Bi}_{2} \mathrm{WO}_{6}$ Nanocomposites with Enhanced Properties of Visible-Light-Driven Photocatalyst
}

Anukorn Phuruangrat ( $\sim$ phuruangrat@gmail.com )

Prince of Songkla University https://orcid.org/0000-0002-7429-0800

Jarupat Teppetcharat

Prince of Songkla University

Panudda Patiphatpanya

Chiang Mai University

Phattranit Dumrongrojthanath

University of Technology Lanna Chiang Rai

Somchai Thongtem

Chiang Mai University

Titipun Thongtem

Chiang Mai University

\section{Research Article}

Keywords: Pd/Bi2WO6 nanocomposites, Photodegradation, Rhodamine B, Scavengers

Posted Date: May 12th, 2021

DOl: https://doi.org/10.21203/rs.3.rs-512226/v1

License: (c) (1) This work is licensed under a Creative Commons Attribution 4.0 International License.

Read Full License 


\section{Abstract}

Heterostructure $\mathrm{Pd} / \mathrm{Bi}_{2} \mathrm{WO}_{6}$ nanocomposites were successful synthesized in ethylene glycol by microwave-assisted deposition method at $300 \mathrm{~W}$ for $10 \mathrm{~min}$. Effect of the loaded Pd on phase, composition, morphology and visible-light-driven photocatalytic properties of $\mathrm{Bi}_{2} \mathrm{WO}_{6}$ was investigated by X-ray diffraction (XRD), scanning electron microscopy (SEM), transmission electron microscopy (TEM), Fast-Fourier-Transform (FFT) diffraction, UV-visible absorption and X-ray photoelectron spectroscopy (XPS). In this research, good distribution of cubic phase of spherical Pd nanoparticles with particle size of 15-20 nm supported on orthorhombic $\mathrm{Bi}_{2} \mathrm{WO}_{6}$ thin nanoplates. The $10 \% \mathrm{Pd} / \mathrm{Bi}_{2} \mathrm{WO}_{6}$ nanocomposites reveal major metallic $\mathrm{Pd}^{0}$ species containing in $\mathrm{Bi}_{2} \mathrm{WO}_{6}$ sample. Microwave can be used to synthesize metallic Pd nanoparticles supporting on top of $\mathrm{Bi}_{2} \mathrm{WO}_{6}$ nanoplates. Photocatalytic activities of $\mathrm{Bi}_{2} \mathrm{WO}_{6}$ loaded with different weight contents of $\mathrm{Pd}$ were monitored through photodegradation of cationic rhodamine $\mathrm{B}(\mathrm{RhB})$ dye under visible light irradiation of a xenon lamp. The $10 \% \mathrm{Pd} / \mathrm{Bi}_{2} \mathrm{WO}_{6}$ nanocomposites have the highest photocatalytic activity because $\mathrm{Pd}$ nanoparticles as electron acceptors promote interfacial charge-transfer through $\mathrm{Pd} / \mathrm{Bi}_{2} \mathrm{WO}_{6}$ heterojunction.

\section{Introduction}

In recent years, semiconductor based photocatalysis as green method is a candidate degradation of harmful organic pollutants in water and air to $\mathrm{CO}_{2}, \mathrm{H}_{2} \mathrm{O}$ and other small molecules at room temperature [1-5]. However, the practical applications of visible-light-driven semiconductor based photocatalysts are still restricted by fast rate of photo-induced charge recombination $[1-3,6,7] . \mathrm{Bi}_{2} \mathrm{WO}_{6}$ as a member of the Aurivillius oxide family is composed of perovskite $\left[\mathrm{WO}_{4}\right]^{2-}$ layers sandwiched between $\left[\mathrm{Bi}_{2} \mathrm{O}_{2}\right]^{2+}$ layers to form internal electric field between the slabs which can lead to enhance the efficient separation of charge carrier and photocatalytic activity $[3,7-9] . \mathrm{Bi}_{2} \mathrm{WO}_{6}$ with narrow band gap of $2.7 \mathrm{eV}$ has been studied as an efficient visible-light-driven photocatalyst due to its high physical and chemical stability and high photostability $[1,8,10]$. Moreover, the photocatalytic activity of bare $\mathrm{Bi}_{2} \mathrm{WO}_{6}$ is limited by fast recombination of photo-induced charge carriers and low efficiency of photo-induced charge transfer [1, 9, 10]. Thus, improving the photocatalytic performance of $\mathrm{Bi}_{2} \mathrm{WO}_{6}$ as photocatalyst is worth to be investigated.

Noble metals have been used as electronic accepter from conduction band of semiconductor to enhance the separation of photo-induced electrons and holes and to promote photocatalytic activity of the semiconductor $[1,11-13]$. There are reports of Pd nanoparticles loaded on semiconductor with enhanced visible-light-driven photocatalytic activity by surface plasmon resonance (SPR) effect, Mott-Schottky interface and increase of valence band edge [12-15]. It is of great significance for synthesizing Pd nanoparticles supported on top of $\mathrm{Bi}_{2} \mathrm{WO}_{6}$ for photodegradation of dye in wastewater under visible light irradiation. 
The present investigation deals with a facile synthesis of novel $\mathrm{Pd} / \mathrm{Bi}_{2} \mathrm{WO}_{6}$ photocatalyst by microwave method. This method consumes short reaction time and cost effective which can lead to fast reduction rate of $\mathrm{Pd}^{2+}$ ions to $\mathrm{Pd}^{0}$ nanoparticles supported on top of $\mathrm{Bi}_{2} \mathrm{WO}_{6}$. Effect of $\mathrm{Pd}$ content on phase, morphology and photocatalytic performance of $\mathrm{Pd} / \mathrm{Bi}_{2} \mathrm{WO}_{6}$ for decomposition of rhodamine $\mathrm{B}(\mathrm{RhB})$ under visible light irradiation was investigated and discussed according to the experimental results.

\section{Experiment}

Bismuth (III) nitrate pentahydrate $\left(\mathrm{Bi}\left(\mathrm{NO}_{3}\right)_{3} \cdot 5 \mathrm{H}_{2} \mathrm{O}\right.$, ACS reagent, $\left.\geq 98.0 \%\right)$, sodium tungstate dihydrate $\left(\mathrm{Na}_{2} \mathrm{WO}_{4} \cdot 2 \mathrm{H}_{2} \mathrm{O}\right.$, ACS reagent, $\left.\geq 99 \%\right)$ and palladium (II) chloride $\left(\mathrm{PdCl}_{2}, \geq 99.9 \%\right)$ were purchased from Sigma-Aldrich Chemical Corporation. Rhodamine $B\left(\mathrm{RhB}, \mathrm{C}_{28} \mathrm{H}_{31} \mathrm{ClN}_{2} \mathrm{O}_{3}, \geq 95 \%\right)$ was purchased from Loba Chemie Pvt. Ltd. They were used without further purification.

Pure $\mathrm{Bi}_{2} \mathrm{WO}_{6}$ nanoplates were synthesized by hydrothermal method. Typically, $0.01 \mathrm{~mol} \mathrm{Bi}\left(\mathrm{NO}_{3}\right)_{3} \cdot 5 \mathrm{H}_{2} \mathrm{O}$ and $0.005 \mathrm{~mol} \mathrm{Na}_{2} \mathrm{WO}_{4} \cdot 2 \mathrm{H}_{2} \mathrm{O}$ were dissolved in $100 \mathrm{ml}$ reverse osmosis (RO) water with continued stirring at room temperature. The $\mathrm{pH}$ of solution was adjusted to 6 by $3 \mathrm{M} \mathrm{NaOH}$ to form white suspension and put in a $200 \mathrm{ml}$ Teflon-lined stainless steel autoclave. The stainless steel autoclave was sealed, heated at $180^{\circ} \mathrm{C}$ for $20 \mathrm{~h}$ in an electric oven and left cooling down to room temperature. The asprepared $\mathrm{Bi}_{2} \mathrm{WO}_{6}$ precipitates were collected, washed and dried for further preparation of $\mathrm{Pd} / \mathrm{Bi}_{2} \mathrm{WO}_{6}$ nanocomposites by microwave-assisted deposition method.

To prepare $\mathrm{Pd} / \mathrm{Bi}_{2} \mathrm{WO}_{6}$ nanocomposites by microwave-assisted deposition method, each of $1 \%, 5 \%$ and $10 \% \mathrm{PdCl}_{2}$ by weight was dissolved in $100 \mathrm{ml}$ ethylene glycol as a reducing reagent. Then, $2.50 \mathrm{~g}$ asprepared $\mathrm{Bi}_{2} \mathrm{WO}_{6}$ nanoplates were added with continued stirring for $30 \mathrm{~min}$. The whole system was transferred in a microwave oven and heated at $300 \mathrm{~W}$ for $10 \mathrm{~min}$. In the end, heterostructure $1 \%, 5 \%$ and $10 \% \mathrm{Pd} / \mathrm{Bi}_{2} \mathrm{WO}_{6}$ nanocomposites were separated, washed by water and ethanol several times and dried for further characterization by X-ray diffraction (XRD), scanning electron microscopy (SEM) connected with energy dispersive X-ray spectrometer (EDS), transmission electron microscopy (TEM), X-ray photoelectron spectroscopy (XPS), Fast-Fourier-Transform (FFT) diffraction and UV-visible absorption spectroscopy.

Photocatalytic activities of heterostructure $\mathrm{Pd} / \mathrm{Bi}_{2} \mathrm{WO}_{6}$ nanocomposites with different weight contents of Pd were investigated by photodegradation of $\mathrm{RhB}$ under visible light irradiation $(\lambda \geq 420 \mathrm{~nm})$ from a xenon lamp with a $420 \mathrm{~nm}$ cutoff filter. $0.2 \mathrm{~g}$ heterostructure $0-10 \% \mathrm{Pd} / \mathrm{Bi}_{2} \mathrm{WO}_{6}$ nanocomposites were suspended in $200 \mathrm{ml}$ of $1 \times 10^{-5} \mathrm{M} \mathrm{RhB}$ solutions ( $\left.\mathrm{pH}=5.2\right)$ with being stirred in the dark for $30 \mathrm{~min}$. During visible light illumination, $5 \mathrm{ml} \mathrm{RhB}$ solution was sampled at a given time interval and spun around to separate heterostructure $\mathrm{Pd} / \mathrm{Bi}_{2} \mathrm{WO}_{6}$ nanocomposites by forcing the heavier solid to the outer edge. The residual concentration of RhB was measured at an absorption peak of $554 \mathrm{~nm}$ by UV-visible spectroscopy. The decolorization efficiency has been calculated by the following. 
Decolorization efficiency $(\%)=\frac{\mathrm{C}_{0}-\mathrm{C}_{t}}{\mathrm{C}_{\mathrm{o}}} \times 100$

$\mathrm{C}_{\mathrm{o}}$ is the initial concentration of $\mathrm{RhB}$ and $\mathrm{C}_{\mathrm{t}}$ is the concentration of $\mathrm{RhB}$ after light irradiation within a period of time $(\mathrm{t})$.

\section{Results And Discussion}

\subsection{Characterization of $\mathrm{Bi}_{2} \mathrm{WO}_{6}$ and $\mathrm{Pd} / \mathrm{Bi}_{2} \mathrm{WO}_{6}$}

X-ray diffraction (XRD) patterns of $\mathrm{Bi}_{2} \mathrm{WO}_{6}$ and $\mathrm{Pd} / \mathrm{Bi}_{2} \mathrm{WO}_{6}$ are shown in Fig. 1. The XRD pattern of pure $\mathrm{Bi}_{2} \mathrm{WO}_{6}$ sample exhibits diffraction peaks at $28.36^{\circ}, 32.96^{\circ}, 47.22^{\circ}, 55.88^{\circ}$ and $58.64^{\circ}$ which correspond to the (131), (200), (202), (331) and (262) planes of orthorhombic $\mathrm{Bi}_{2} \mathrm{WO}_{6}$ phase comparing to the JCPDS No. 39-0256 [16]. The XRD patterns of $\mathrm{Pd} / \mathrm{Bi}_{2} \mathrm{WO}_{6}$ nanocomposites show addition diffraction peaks at $40.11^{\circ}$ which can be identified to the (111) plane of metallic cubic Pd phase (JCPDS No. 46-1043 [16]). There is no change in orthorhombic structure of $\mathrm{Bi}_{2} \mathrm{WO}_{6}$ phase in the $\mathrm{Pd} / \mathrm{Bi}_{2} \mathrm{WO}_{6}$ nanocomposites. These results indicate that metallic $\mathrm{Pd}$ nanoparticles deposited on top of $\mathrm{Bi}_{2} \mathrm{WO}_{6}$ nanoplates. No other diffraction peaks were detected in both XRD patterns of $\mathrm{Bi}_{2} \mathrm{WO}_{6}$ and $\mathrm{Pd} / \mathrm{Bi}_{2} \mathrm{WO}_{6}$. The crystallite size of $\mathrm{Pd}$ in $\mathrm{Pd} / \mathrm{Bi}_{2} \mathrm{WO}_{6}$ nanocomposites was calculated from the Scherrer's equation as follows.

$D=K \lambda / \beta \cos \theta$

$D$ is the crystallite size $(\mathrm{nm}), \mathrm{K}$ is the shape factor and equals 0.94 for spherical particle, $\lambda$ is the wavelength of $\mathrm{Cu} \mathrm{K}$ line $(\lambda=0.154056 \mathrm{~nm}), \beta$ is the full width at half maximum (FWHM) in radian and $\theta$ is the Bragg's angle $[3,17,18]$. The crystallite size of $\mathrm{Pd}$ nanoparticles containing in $10 \% \mathrm{Pd} / \mathrm{Bi}_{2} \mathrm{WO}_{6}$ nanocomposites is $8.53 \mathrm{~nm}$.

SEM images of $\mathrm{Bi}_{2} \mathrm{WO}_{6}$ and $\mathrm{Pd} / \mathrm{Bi}_{2} \mathrm{WO}_{6}$ are shown in Fig. 2. The as-prepared $\mathrm{Bi}_{2} \mathrm{WO}_{6}$ sample was composed of nanoplates with 100-200 nm in diameter and an average thickness of about $20 \mathrm{~nm}$. The surface of $\mathrm{Bi}_{2} \mathrm{WO}_{6}$ nanoplates is smooth. Upon being loaded with $\mathrm{Pd}$, the morphologies of $1 \%, 5 \%$ and $10 \% \mathrm{Pd} / \mathrm{Bi}_{2} \mathrm{WO}_{6}$ nanocomposites remain unchanged. SEM image of $10 \% \mathrm{Pd} / \mathrm{Bi}_{2} \mathrm{WO}_{6}$ nanocomposites presents clear $\mathrm{Pd}$ nanoparticles with particle size of $<20 \mathrm{~nm}$ deposited on the surface of $\mathrm{Bi}_{2} \mathrm{WO}_{6}$ synthesized by microwave-assisted precipitation method. The elemental constituents containing in $10 \%$ $\mathrm{Pd} / \mathrm{Bi}_{2} \mathrm{WO}_{6}$ nanocomposites were analyzed by energy dispersive $\mathrm{X}$-ray spectroscopy (EDS) and the elemental distribution was analyzed by EDS mapping as the results shown in Fig. 3. The EDS spectrum of $10 \% \mathrm{Pd} / \mathrm{Bi}_{2} \mathrm{WO}_{6}$ nanocomposites contains $\mathrm{Pd}, \mathrm{Bi}, \mathrm{W}$ and $\mathrm{O}$. The EDS analysis shows that $\mathrm{Pd}$ in $10 \%$ $\mathrm{Pd} / \mathrm{Bi}_{2} \mathrm{WO}_{6}$ nanocomposites is $8.57 \%$ by weight. The EDS mapping of $10 \% \mathrm{Pd} / \mathrm{Bi}_{2} \mathrm{WO}_{6}$ nanocomposites shows uniform distribution of metallic Pd nanoparticles across the whole sample. 
Figure 4 shows TEM images of the as-prepared $\mathrm{Bi}_{2} \mathrm{WO}_{6}$ sample and $\mathrm{Pd} / \mathrm{Bi}_{2} \mathrm{WO}_{6}$ nanocomposites with different contents of metallic Pd particles loaded on top. As shown in Fig. $4 \mathrm{a}$, the $\mathrm{Bi}_{2} \mathrm{WO}_{6}$ sample exhibits nanoplates with edge of $200 \times 100 \mathrm{~nm}$. The SAED pattern of single phase of orthorhombic $\mathrm{Bi}_{2} \mathrm{WO}_{6}$ nanoplate (Fig. 4b) shows spots of electron diffraction pattern, certifying a single crystalline nanoplate. The pattern can be indexed to the (200), (220) and (020) planes of orthorhombic $\mathrm{Bi}_{2} \mathrm{WO}_{6}$ which is in good agreement with the XRD standard $[19,20]$. A set of diffraction spots was specified as the [001] zone axis of orthorhombic $\mathrm{Bi}_{2} \mathrm{WO}_{6}$. Thus, the exposed facet of $\mathrm{Bi}_{2} \mathrm{WO}_{6}$ nanoplate is $(001)$ plane $[19,20]$. Figure $4 \mathrm{c}$ and $\mathrm{d}$ of $5 \%$ and $10 \%$ of $\mathrm{Pd} / \mathrm{Bi}_{2} \mathrm{WO}_{6}$ samples shows $\mathrm{Pd}$ fine dispersive nanoparticles with size of $15-20$ $\mathrm{nm}$ on top of $\mathrm{Bi}_{2} \mathrm{WO}_{6}$ nanoplates. They should be noted that a number of Pd nanoparticles were increased with the progressive increase of $\mathrm{PdCl}_{2}$ content. The average particle sizes of $\mathrm{Pd}$ counted for 100 particles were $9.97 \pm 2.17$ and $11.22 \pm 2.53 \mathrm{~nm}$ for $5 \% \mathrm{Pd} / \mathrm{Bi}_{2} \mathrm{WO}_{6}$ and $10 \% \mathrm{Pd} / \mathrm{Bi}_{2} \mathrm{WO}_{6}$, respectively. Figure $4 \mathrm{e}$ shows a high-resolution TEM image of $10 \% \mathrm{Pd} / \mathrm{Bi}_{2} \mathrm{WO}_{6}$ nanocomposites which revealed the Schottky barriers between metallic $\mathrm{Pd}$ nanoparticles and $\mathrm{Bi}_{2} \mathrm{WO}_{6}$ nanoplates and enhanced the photocatalytic performance of heterostructure $\mathrm{Pd} / \mathrm{Bi}_{2} \mathrm{WO}_{6}$ nanocomposites $[1,6,8,9]$. Obviously, the lattice fringe spaces of $3.18 \AA$ and $2.25 \AA$ were well-indexed to the (131) plane of orthorhombic $\mathrm{Bi}_{2} \mathrm{WO}_{6}$ structure and the (111) plane of cubic Pd structure. The Fast-Fourier-Transform (FFT) diffraction pattern of a Pd nanoparticle as shown in Fig. $4 \mathrm{f}$ appears as clear diffraction spots with systematic alignment of the single crystalline nanoparticle.

The chemical states of $\mathrm{Pd}$ nanoparticles on top of $\mathrm{Bi}_{2} \mathrm{WO}_{6}$ nanoplates were investigated by XPS. The survey XPS spectrum of $10 \% \mathrm{Pd} / \mathrm{Bi}_{2} \mathrm{WO}_{6}$ (Fig. 5a) shows that the heterostructure $10 \% \mathrm{Pd} / \mathrm{Bi}_{2} \mathrm{WO}_{6}$ nanocomposites are composed of $\mathrm{Pd} 3 \mathrm{~d}, \mathrm{Bi} 4 \mathrm{f}, \mathrm{O} 1 \mathrm{~s}$ and $\mathrm{W} 4 \mathrm{f}$ elements corresponding to the above EDS results. The $\mathrm{Pd} 3 \mathrm{~d}$ spectrum of $10 \% \mathrm{Pd} / \mathrm{Bi}_{2} \mathrm{WO}_{6}$ (Fig. $5 \mathrm{~b}$ ) contained two signals of $\mathrm{Pd} 3 \mathrm{~d}_{5 / 2}$ and $\mathrm{Pd} 3 \mathrm{~d}_{3 / 2}$ at $335.27 \mathrm{eV}$ and $340.60 \mathrm{eV}$, respectively. The signals certified that $\mathrm{Pd}$ species in the catalyst mainly existed as metallic Pd nanoparticles [12, 13, 21-23]. Moreover, the peaks at higher binding energies are

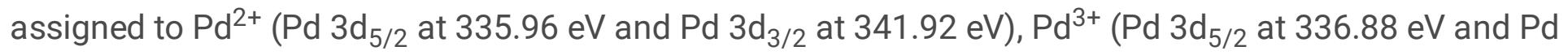
$3 d_{3 / 2}$ at $\left.342.49 \mathrm{eV}\right)$ and $\mathrm{Pd}^{4+}\left(\mathrm{Pd} 3 \mathrm{~d}_{5 / 2}\right.$ at $337.93 \mathrm{eV}$ and $\mathrm{Pd} 3 \mathrm{~d}_{3 / 2}$ at $\left.343.24 \mathrm{eV}\right)$ [13, 21-23]. Figure $5 \mathrm{c}$ shows two binding energy peaks of $159.42 \mathrm{eV}$ and $164.76 \mathrm{eV}$ in accordance with the $B i 4 f_{7 / 2}$ and $B i 4 f_{5 / 2}$ levels, respectively. Thus, $\mathrm{Bi}$ species in $\mathrm{Bi}_{2} \mathrm{WO}_{6}$ are attributed to the typical $\mathrm{Bi}^{3+}$ ions $[1,8,9,12,19,20]$. The XPS spectrum of $W 4 f$ (Fig. $5 d$ ) shows two main binding energies at $35.67 \mathrm{eV}$ for $W_{4 / 2}$ and 37.83 $\mathrm{eV}$ for $\mathrm{W}_{4 / 2}$, certifying the existence of $\mathrm{W}^{6+}$ oxidation state $[1,8,9,19,20]$. The 01 s core level (Fig. $5 \mathrm{e}$ ) can be de-convoluted into three peaks, which include bonds of $\mathrm{Bi}-\mathrm{O}$ at $530.33 \mathrm{eV}, \mathrm{W}-\mathrm{O}$ at $531.11 \mathrm{eV}$ and $\mathrm{O}-\mathrm{H}$ on top of $\mathrm{Bi}_{2} \mathrm{WO}_{6}$ at $532.37 \mathrm{eV}[1,19,20]$.

The optical properties of photocatalysts were analyzed by UV-visible spectroscopy as the results shown in Fig. 6. UV-visible absorption of pure $\mathrm{Bi}_{2} \mathrm{WO}_{6}$ sample (Fig. 6a) shows an excellent absorption in UVvisible region due to the intrinsic energy gap of $\mathrm{Bi}_{2} \mathrm{WO}_{6}$ [24-26]. Comparing to $\mathrm{Bi}_{2} \mathrm{WO}_{6}, 10 \% \mathrm{Pd} / \mathrm{Bi}_{2} \mathrm{WO}_{6}$ shows higher absorption in visible light because of the localized SPR effect of Pd nanoparticles 
supported on top of $\mathrm{Bi}_{2} \mathrm{WO}_{6}$ nanoplates [27-29]. The results indicate that heterostructure $\mathrm{Pd} / \mathrm{Bi}_{2} \mathrm{WO}_{6}$ nanocomposites absorbed visible light which can lead to generate more charge carriers and to improve photocatalytic activity [26-29]. Figure $6 \mathrm{~b}$ shows the plot of (ahv) ${ }^{2}$ versus hv of pure $\mathrm{Bi}_{2} \mathrm{WO}_{6}$ and $10 \%$ $\mathrm{Pd} / \mathrm{Bi}_{2} \mathrm{WO}_{6}$ samples by Kubelka-Munk equation $[24,26]$. The band gaps of pure $\mathrm{Bi}_{2} \mathrm{WO}_{6}$ and $10 \%$ $\mathrm{Pd} / \mathrm{Bi}_{2} \mathrm{WO}_{6}$ samples are $2.48 \mathrm{eV}$ and $2.54 \mathrm{eV}$, respectively.

The visible-light-driven photocatalytic performance of pure $\mathrm{Bi}_{2} \mathrm{WO}_{6}$ and $\mathrm{Bi}_{2} \mathrm{WO}_{6}$ doped with different contents of Pd was investigated for photodegradation of RhB. Figure 7 shows UV-visible spectra of RhB solution over $10 \% \mathrm{Pd} / \mathrm{Bi}_{2} \mathrm{WO}_{6}$ for different lengths of irradiation time. They can be seen that $\lambda_{\max }$ of $\mathrm{RhB}$ at $554 \mathrm{~nm}$ was significantly decreased with increasing in irradiation time and was slightly blue shifted because of deethylation of ethyl group and decomposition of $\operatorname{RhB}[20,30,31]$.

The photocatalytic performance of pure $\mathrm{Bi}_{2} \mathrm{WO}_{6}$ and $\mathrm{Bi}_{2} \mathrm{WO}_{6}$ doped with different contents of $\mathrm{Pd}$ under visible light irradiation was estimated through the change of $\mathrm{RhB}$ concentration as a function of irradiation time (Fig. 8a). The photolysis of pure RhB solution was carried out under visible-light irradiation. The RhB solution was highly stable and was not degraded under visible light irradiation within $120 \mathrm{~min}$. Clearly, the degradation efficiency of $\mathrm{Bi}_{2} \mathrm{WO}_{6}$ was improved by being loaded with $\mathrm{Pd}$. The degradation efficiencies of $\mathrm{Pd} / \mathrm{Bi}_{2} \mathrm{WO}_{6}$ samples were improved with increasing in $\mathrm{Pd}$ content from $1-10 \%$ by weight. $\mathrm{Bi}_{2} \mathrm{WO}_{6}$ could degrade $48.71 \% \mathrm{RhB}$ under light irradiation within $120 \mathrm{~min}$. In contrast, $10 \%$ $\mathrm{Pd} / \mathrm{Bi}_{2} \mathrm{WO}_{6}$ sample could degrade almost $100 \%$ of $\mathrm{RhB}$ under visible light irradiation within $120 \mathrm{~min}$. This sample has the highest activity for RhB degradation.

The kinetic degradation of $\mathrm{RhB}$ over $\mathrm{Bi}_{2} \mathrm{WO}_{6}$ and $\mathrm{Pd} / \mathrm{Bi}_{2} \mathrm{WO}_{6}$ nanosamples was also investigated by the pseudo-first-order equation as follows.

$\ln \left(C_{0} / C_{t}\right)=k t$

, where $\mathrm{k}$ is the first-order rate constant, $\mathrm{C}_{\mathrm{o}}$ is the initial concentration and $\mathrm{C}_{\mathrm{t}}$ is the concentration at a time (t) $[1,3,11,13,14,17,20]$. The photodegradation of $\mathrm{RhB}$ by $\mathrm{Bi}_{2} \mathrm{WO}_{6}$ and $\mathrm{Pd} / \mathrm{Bi}_{2} \mathrm{WO}_{6}$ follows the pseudofirst order kinetics (Fig. 8b). The degradation rate constant over $10 \mathrm{wt} \% \mathrm{Pd} / \mathrm{Bi}_{2} \mathrm{WO}_{6}$ nanocomposites $\left(0.0270 \mathrm{~min}^{-1}\right)$ is 4.79 times that over pure $\mathrm{Bi}_{2} \mathrm{WO}_{6}$ nanoplates $\left(5.64 \times 10^{-3} \mathrm{~min}^{-1}\right)$. These results were suggested that $10 \% \mathrm{Pd} / \mathrm{Bi}_{2} \mathrm{WO}_{6}$ nanocomposites exhibited the highest photocatalytic performance for $\mathrm{RhB}$ degradation. The photostability of reused $10 \% \mathrm{Pd} / \mathrm{Bi}_{2} \mathrm{WO}_{6}$ nanocomposites was further investigated for five recycles as the results shown in Fig. 9. There is no obvious decline in photodegradation of RhB after five reaction runs. Thus, $10 \% \mathrm{Pd} / \mathrm{Bi}_{2} \mathrm{WO}_{6}$ nanocomposites have excellent photostability and photocorrosion resistance under visible light irradiation.

During photodegradation of $\mathrm{RhB}$ solutions containing $10 \% \mathrm{Pd} / \mathrm{Bi}_{2} \mathrm{WO}_{6}$ nanocomposites under visible light irradiation, isopropanol (IPA), benzoquinone (BQ) and ethylenediaminetetraacetic acid disodium salt (EDTA-2Na) were also added for scavenging hydroxyl radical $\left({ }^{\bullet} \mathrm{OH}\right)$, superoxide radical $\left({ }^{\bullet} \mathrm{O}_{2}^{-}\right)$and 
photogenerated hole $\left(\mathrm{h}^{+}\right)$, respectively [32-35]. The photodegradation of RhB (Fig. 10) was significantly decreased to $35.78 \%$ and $25.35 \%$ for the addition of IPA and BQ. But for the addition of EDTA-2Na, the photodegradation of RhB was still quite high. According to the results, $\bullet \mathrm{OH}$ and $\boldsymbol{O}_{2}{ }^{-}$are the main active species for $\mathrm{RhB}$ degradation over $10 \% \mathrm{Pd} / \mathrm{Bi}_{2} \mathrm{WO}_{6}$ nanocomposites.

Based on the above results and discussion, a mechanism of the enhanced photocatalytic performance of $\mathrm{Pd} / \mathrm{Bi}_{2} \mathrm{WO}_{6}$ was proposed (Fig. 11). Electrons were excited from valence band (VB) to conduction band (CB) while holes were induced in $\mathrm{VB}$ of $\mathrm{Bi}_{2} \mathrm{WO}_{6}$ under visible light irradiation $[1,9,11,14,19,20]$.

Subsequently, the excited electrons and photo-induced holes were transferred to the surface of $\mathrm{Bi}_{2} \mathrm{WO}_{6}$ photocatalyst and reacted with $\mathrm{O}_{2}$ and $\mathrm{H}_{2} \mathrm{O} / \mathrm{OH}^{-}$to produce active superoxide anion radical $\left({ }^{\bullet} \mathrm{O}_{2}{ }^{-}\right)$and hydroxyl radical $(\bullet \mathrm{OH})$ for degradation of $\mathrm{RhB}$ molecules $[1,9,11,14,19,20]$.

$\mathrm{Bi}_{2} \mathrm{WO}_{6}+\mathrm{hv} \rightarrow \mathrm{e}^{-} \mathrm{CB}^{+} \mathrm{h}^{+} \mathrm{VB}$

$\mathrm{Pd}+\mathrm{e}^{-} \mathrm{CB}^{-} \rightarrow \mathrm{e}^{-} \mathrm{Pd}$

$\mathrm{e}^{-} \mathrm{Pd}+\mathrm{O}_{2} \rightarrow \bullet^{\bullet} \mathrm{O}_{2}^{-}$

$\mathrm{h}^{+}{ }_{\mathrm{VB}}+\mathrm{H}_{2} \mathrm{O} / \mathrm{OH}^{-} \rightarrow \bullet \mathrm{OH}$

$\bullet \mathrm{O}_{2}{ }^{-} / \bullet \mathrm{OH}+\mathrm{RhB}$ dye $\rightarrow$ Degraded products

Thus, $\mathrm{Pd}$ nanoparticles on top of $\mathrm{Bi}_{2} \mathrm{WO}_{6}$ nanoplates act as electron acceptors, promote interfacial charge-transfer kinetics through the metal - semiconductor interface $[1,9,11,12,14,19,20]$, improve the separation of electron - hole pairs and enhance the photocatalytic activity of $\mathrm{Pd} / \mathrm{Bi}_{2} \mathrm{WO}_{6}$ nanocomposites.

\section{Conclusions}

Visible-light-driven $\mathrm{Bi}_{2} \mathrm{WO}_{6}$ nanoplates containing different weight contents of $\mathrm{Pd}$ nanoparticles were successfully synthesized by microwave-assisted deposition method. XRD, TEM, SEM and XPS analyses showed that the products were spherical metallic $\mathrm{Pd}$ nanoparticles supported on top of $\mathrm{Bi}_{2} \mathrm{WO}_{6}$ thin nanoplates. The photocatalytic activities of $\mathrm{Bi}_{2} \mathrm{WO}_{6}$ and $\mathrm{Pd} / \mathrm{Bi}_{2} \mathrm{WO}_{6}$ were investigated through photodegradation of $\mathrm{RhB}$ under visible light irradiation. The $10 \% \mathrm{Pd} / \mathrm{Bi}_{2} \mathrm{WO}_{6}$ nanocomposites have photocatalytic degradation of rhodamine $\mathrm{B}$ for two times of the pure $\mathrm{Bi}_{2} \mathrm{WO}_{6}$ phase by forming $\mathrm{Pd}$ nanoparticle $-\mathrm{Bi}_{2} \mathrm{WO}_{6}$ nanoplate Schottky barriers. In this research, $10 \% \mathrm{Pd} / \mathrm{Bi}_{2} \mathrm{WO}_{6}$ nanocomposites are very stable and have very high corrosion resistance under visible light irradiation. The $10 \% \mathrm{Pd} / \mathrm{Bi}_{2} \mathrm{WO}_{6}$ nanocomposites are considered as a promising photocatalyst for wastewater treatment.

\section{Declarations}




\section{Acknowledgement}

We are extremely grateful to the Prince of Songkla University, Hat Yai, Songkhla 90112, Thailand for providing financial support the contact no. SCl6202009S.

\section{References}

1. Y. Zhou, P. Lv, W. Zhang, X. Meng, H. He, X. Zeng, X. Shen, Appl. Surf. Sci. 457, 925 (2018)

2. Q. Dai, Y. Xia, L. Jiang, W. Li, J. Wang, J. Chen, Int. J. Electrochem. Sci. 7, 12895 (2012)

3. M.H. Selvi, P.R. Vang, M. Ashok, Optik 173, 227 (2018)

4. H. Azizi-Toupkanloo, M. Karimi-Nazarabad, G.R. Amini, A. Darroudi, Sol. Energy 196, 653 (2020)

5. M. Karimi-Nazarabad, E.K. Goharshadi, M. Aziznezhad, ChemistrySelect 4, 14175 (2019)

6. M. Karimi-Nazarabad, E.K. Goharshadi, S.J. Mahdizadeh, J. Phys. Chem. C 123, 26106 (2019)

7. H. Sun, Z. Tian, G. Zhou, J. Zhang, P. Li, Appl. Surf. Sci. 469, 125 (2019)

8. F. Xu, C. Xu, H. Chen, D. Wu, Z. Gao, X. Ma, Q. Zhang, K. Jiang, J. Alloy. Compd. 780, 634 (2019)

9. T. Huang, Y. Li, X. Wu, K. Lv, Q. Li, M. Li, D. Du, H. Ye, Chinese J. Catal. 39, 718 (2018)

10. J. Xiao, W. Dong, C. Song, Y. Yu, L. Zhang, C. Li, Y. Yin, Mater. Sci. Semicond. Process. 40, 463 (2015)

11. Y. Guo, J. Wei, T. Yang, Z. Lv, Z. Xu, Optik 180, 285 (2019)

12. L.Z. Ren, D.E. Zhang, X.Y. Hao, X. Xiao, Y.X. Jiang, J.Y. Gong, F. Zhang, X. Zhang, Z.W. Tong, Mater. Res. Bull. 94, 183 (2017)

13. X. Meng, Z. Zhang, Appl. Surf. Sci. 392, 169 (2017)

14. X. Meng, Z. Li, Z. Zhang, Mater. Res. Bull. 99, 471 (2018)

15. C. Lavorato, P. Argurio, T.F. Mastropietro, G. Pirri, T. Poerio, R. Molinari, J. Catal. 353, 152 (2017)

16. Powder Diffract. J.C.P.D.S. File, Internat. Centre Diffract. Data, PA 19073-3273, U.S.A. (2001)

17. A. Phuruangrat, S. Thongtem, T. Thongtem, Mater. Lett. 196, 61 (2017)

18. A. Phuruangrat, B. Kuntalue, S. Thongtem, T. Thongtem, Mater. Lett. 167, 65 (2016)

19. A. Phuruangrat, A. Maneechote, P. Dumrongrojthanath, N. Ekthammathat, S. Thongtem, T. Thongtem, Mater. Lett. 159, 289 (2015)

20. P. Dumrongrojthanath, A. Phuruangrat, P. Junploy, S. Thongtem, T. Thongtem, Res. Chem. Intermed. 42, 1651 (2016)

21. J.X. Tang, Q.S. Chen, L.X. You, H.G. Liao, S.G. Sun, S.G. Zhou, Z.N. Xu, Y.M. Chen, G.C. Guo, J. Mater. Chem. A 6, 2327 (2018)

22. G.L. Chiarello, J.D. Grunwaldt, D. Ferri, F. Krumeich, C. Oliva, L. Forni, A. Baiker, J. Catal. 252, 127 (2007)

23. H. Yang, Z. Tang, K. Wang, W. Wu, Y. Chen, Z. Ding, Z. Liu, S. Chen, J. Colloid Interface Sci. 528, 18 (2018) 
24. C. Huang, L. Chen, H. Li, Y. Mu, Z. Yang, RSC Adv. 9, 27768 (2019)

25. A. Phuruangrat, P. Dumrongrojthanath, N. Ekthammathat, S. Thongtem, T. Thongtem, J. Nanomater. 2014,138561 (2014)

26. F. Ma, Q. Yang, Z. Wang, Y. Liu, J. Xin, J. Zhang, Y. Hao, L. Li, RSC Adv. 8, 15853 (2018)

27. J. Shen, J. Xue, Z. Chen, J. Ni, B. Tang, G. He, H. Chen, J. Mater. Sci. 53, 4848 (2018)

28. A. Phuruangrat, P. Keereesaensuk, K. Karthik, P. Dumrongrojthanath, N. Ekthammathat, S. Thongtem, T. Thongtem, J. Inorg. Organomet. Polym Mater. 30, 1033 (2020)

29. S. Wu, N. Tan, D. Lan, B. Yi,. Int. J. Photoenergy 2018, 8138064 (2018)

30. Y. Shang, Y. Cui, R. Shi, P. Yang, Mater. Sci. Semicond. Process. 89, 240 (2019)

31. F. Chang, Q. Xu, F. Wu, M. Jiao, B. Deng, X. Hu, Mater. Sci. Semicond. Process. 80, 1 (2018)

32. Q. Wang, S. Yu, W. Qin, X. Wu, Nanoscale Adv. 2, 274 (2020)

33. S.J. Shah, A. Khan, N. Naz, A. Ismai, M. Zahid, M.S. Khan, M. Awais, S.H. Ismail, I. Bakhtiar, B. Khan, N. Ahmad, A. Ali, S. Zada, Ali, Spectrochim. Acta A 236, 118314 (2020)

34. Z. Gao, X. Qu, Construction of $\mathrm{ZnTiO}_{3} / \mathrm{Bi}_{4} \mathrm{NbO}_{8} \mathrm{Cl}$. Nanoscale Res. Lett. 15, 64 (2020)

35. S. Dursun, IC. Kaya, M. Kocabaş, H. Akyildiz, V. Kalem, Int J Appl Ceram Technol. 17, 1479 (2020)

\section{Figures}




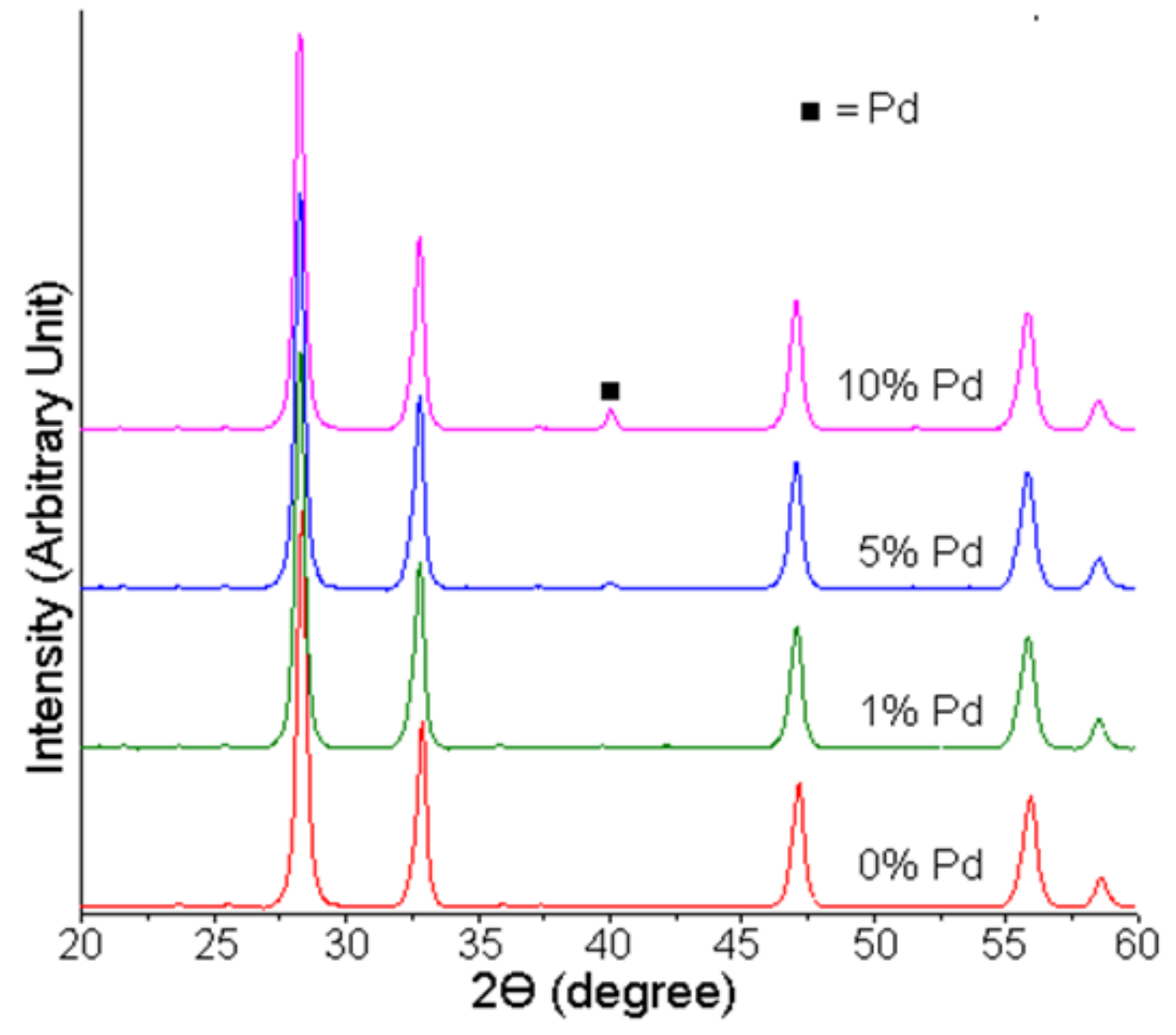

Figure 1

XRD patterns of $0-10 \% \mathrm{Pd} / \mathrm{Bi} 2$ WO6 samples. 


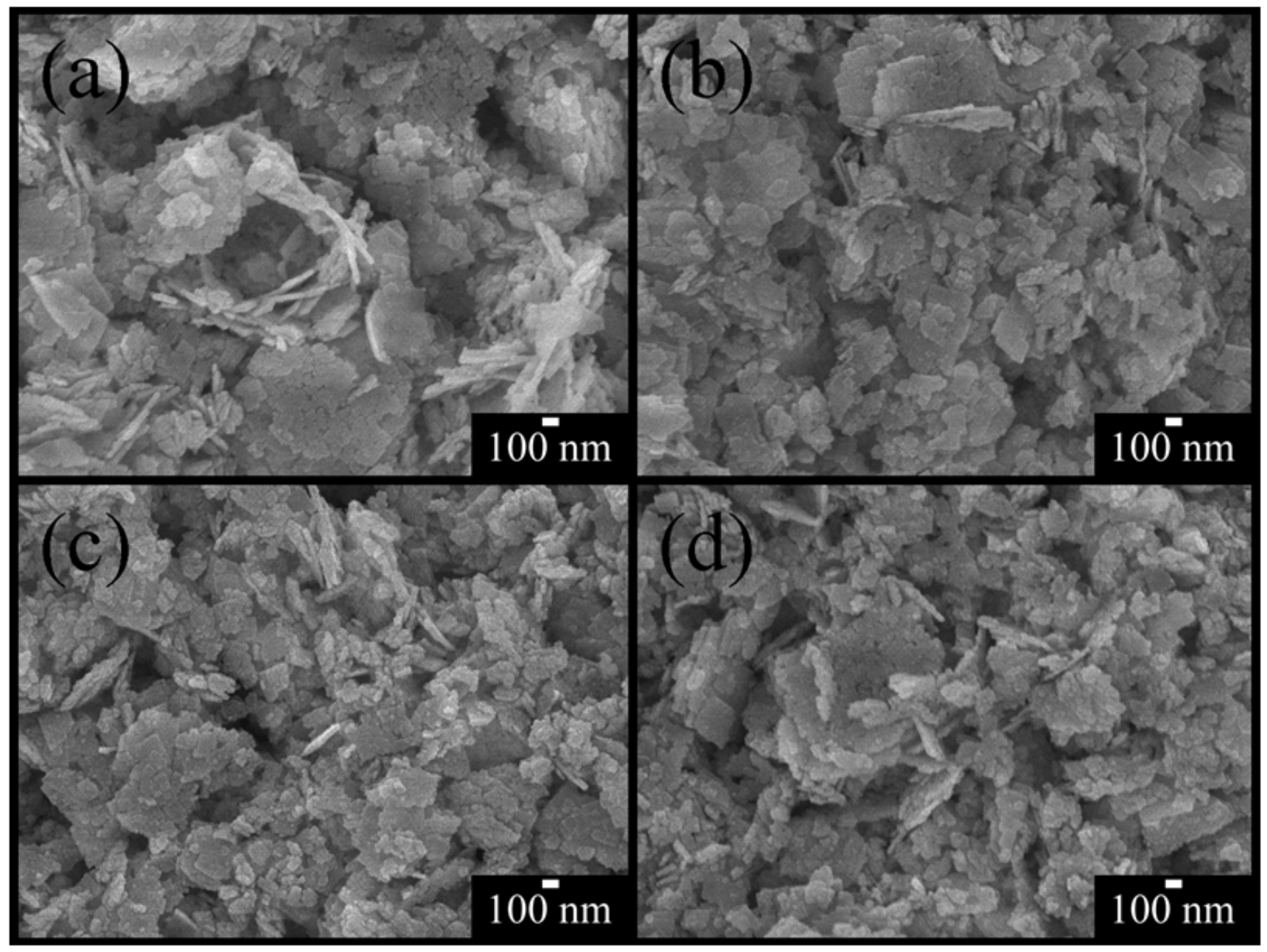

Figure 2

SEM images of (a) Bi2WO6, (b) 1\% Pd/Bi2WO6, (c) 5\% Pd/Bi2WO6 and (d) 10\% Pd/Bi2WO6. 


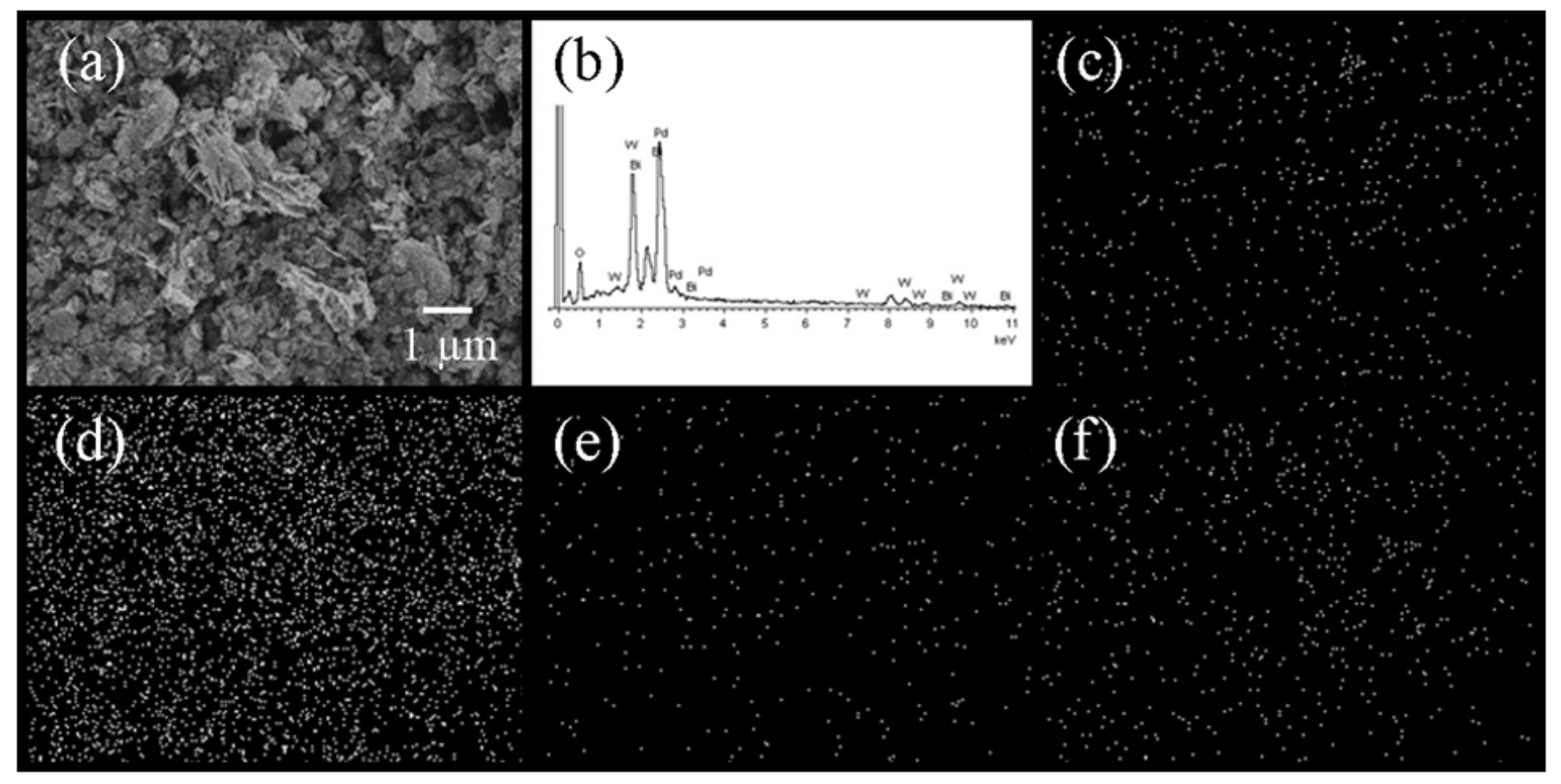

Figure 3

(a) SEM image and (b) EDS spectrum of 10\% Pd/Bi2WO6 nanocomposites. EDS mapping of (c) Pd, (d) $\mathrm{Bi}$, (e) W and (f) $\mathrm{O}$ containing in 10\% Pd/Bi2WO6 nanocomposites. 


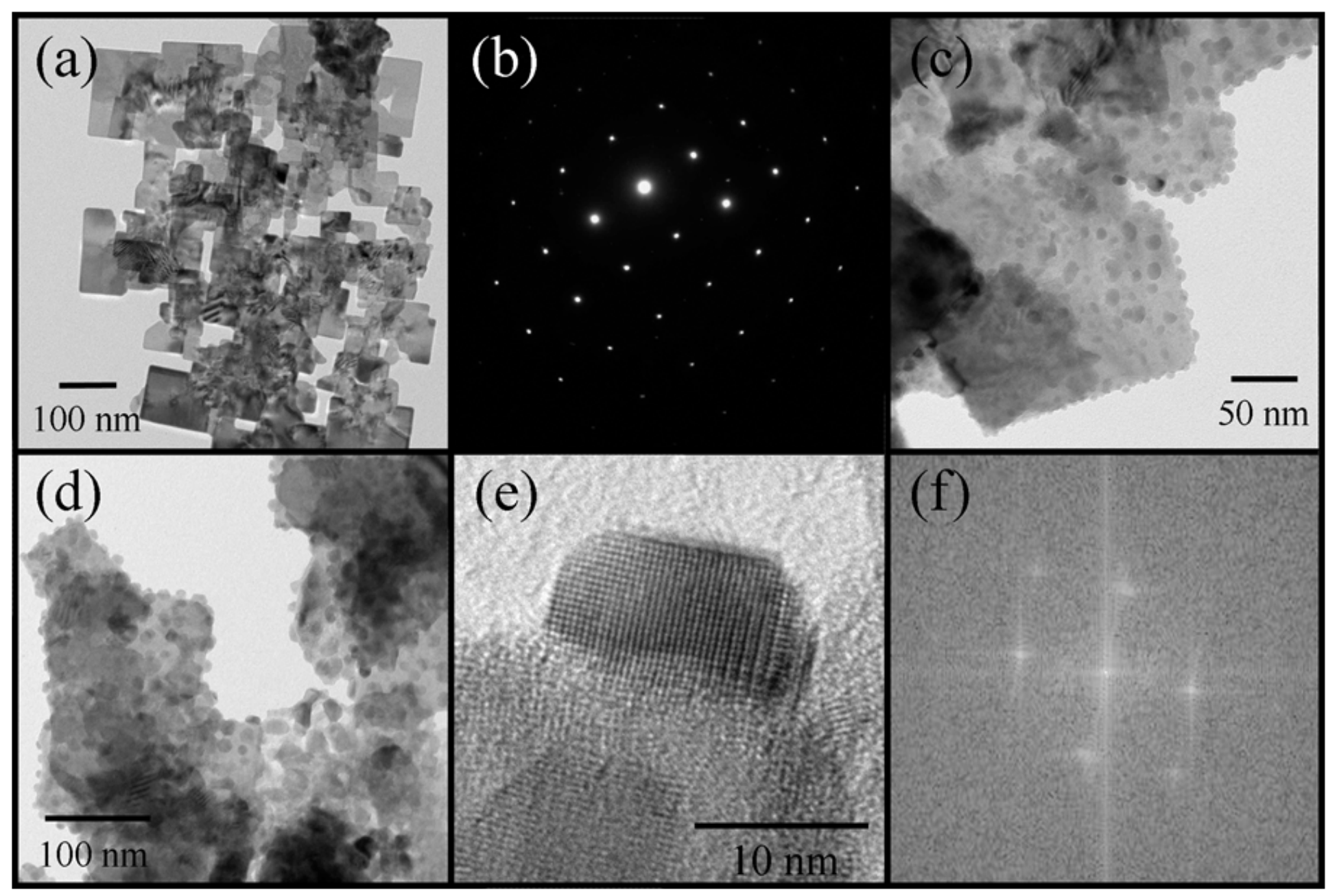

Figure 4

TEM images, SAED pattern, HRTEM image and FFT pattern of (a, b) Bi2WO6, (c) 5\% Pd/Bi2WO6 and (d-f) $10 \%$ Pd/Bi2WO6. 

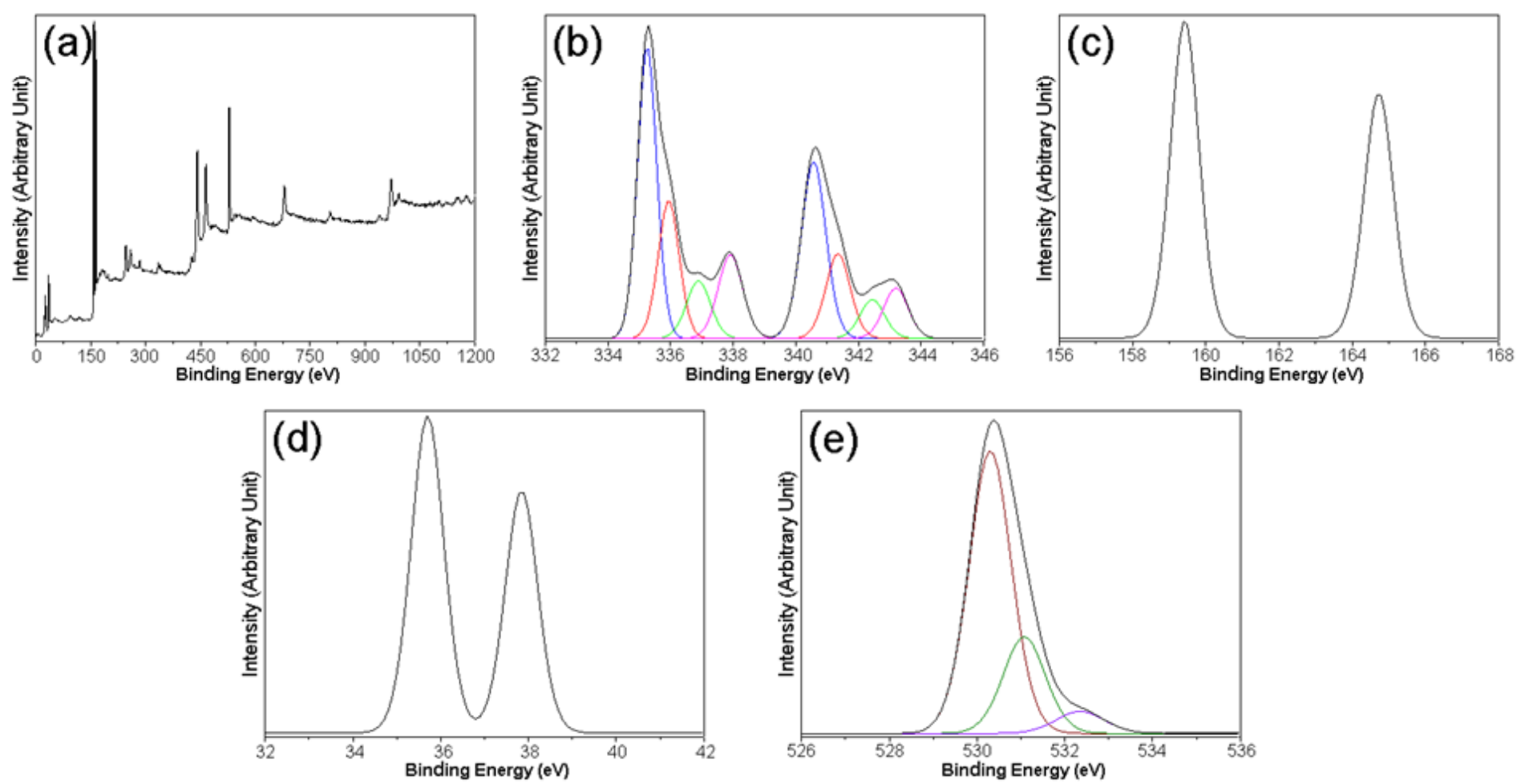

Figure 5

XPS spectra of (a) full survey scan, (b) Pd 4d, (c) Bi 4f, (d) W 4f, (e) 0 1s of as-synthesized heterojunction 10\% Pd/Bi2WO6 nanocomposites. 

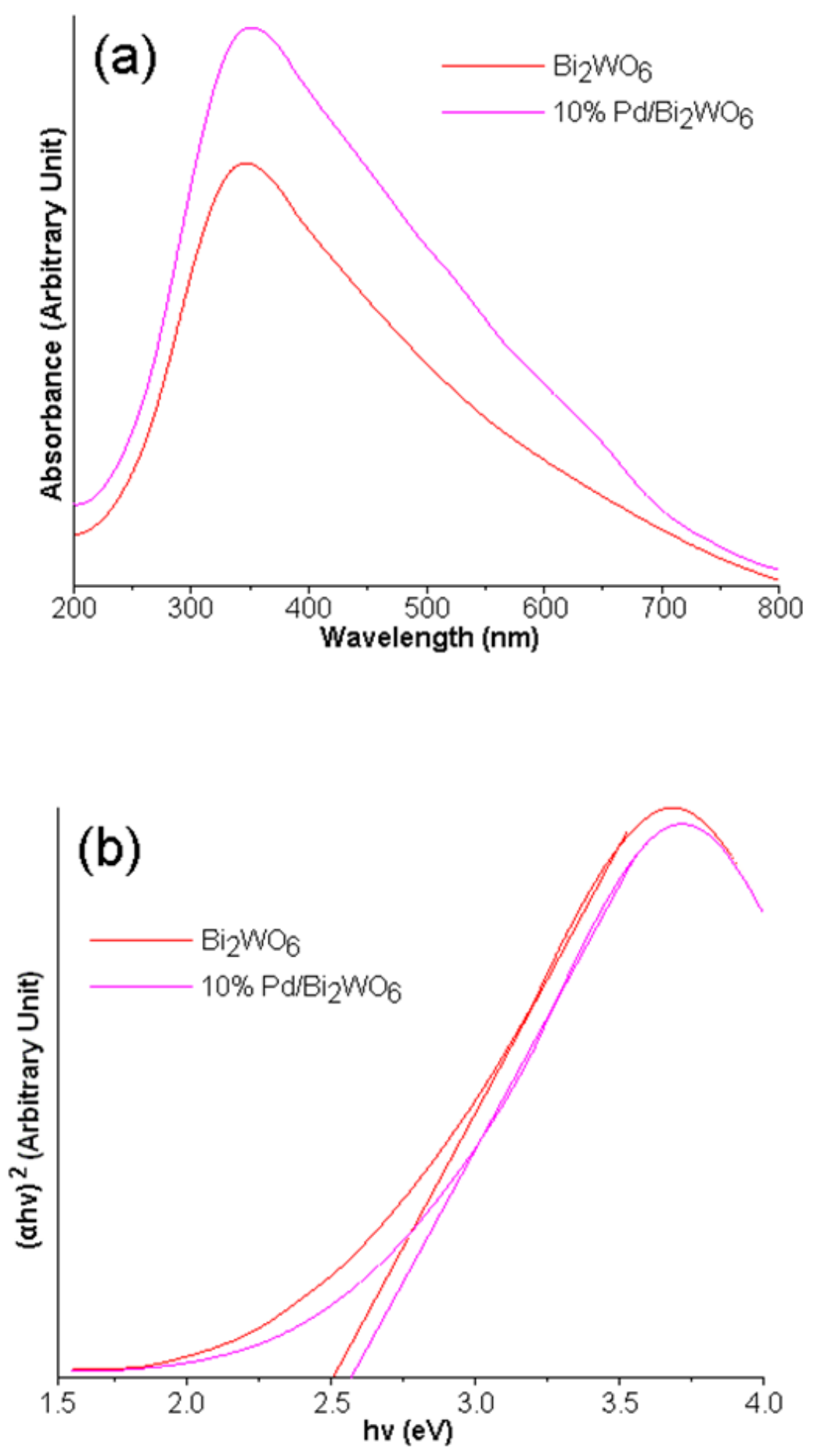

\section{Figure 6}

(a) UV-visible spectra and (b) the plot of (ahv)2 versus hv of Bi2WO6 and 10\% Pd/Bi2WO6. 


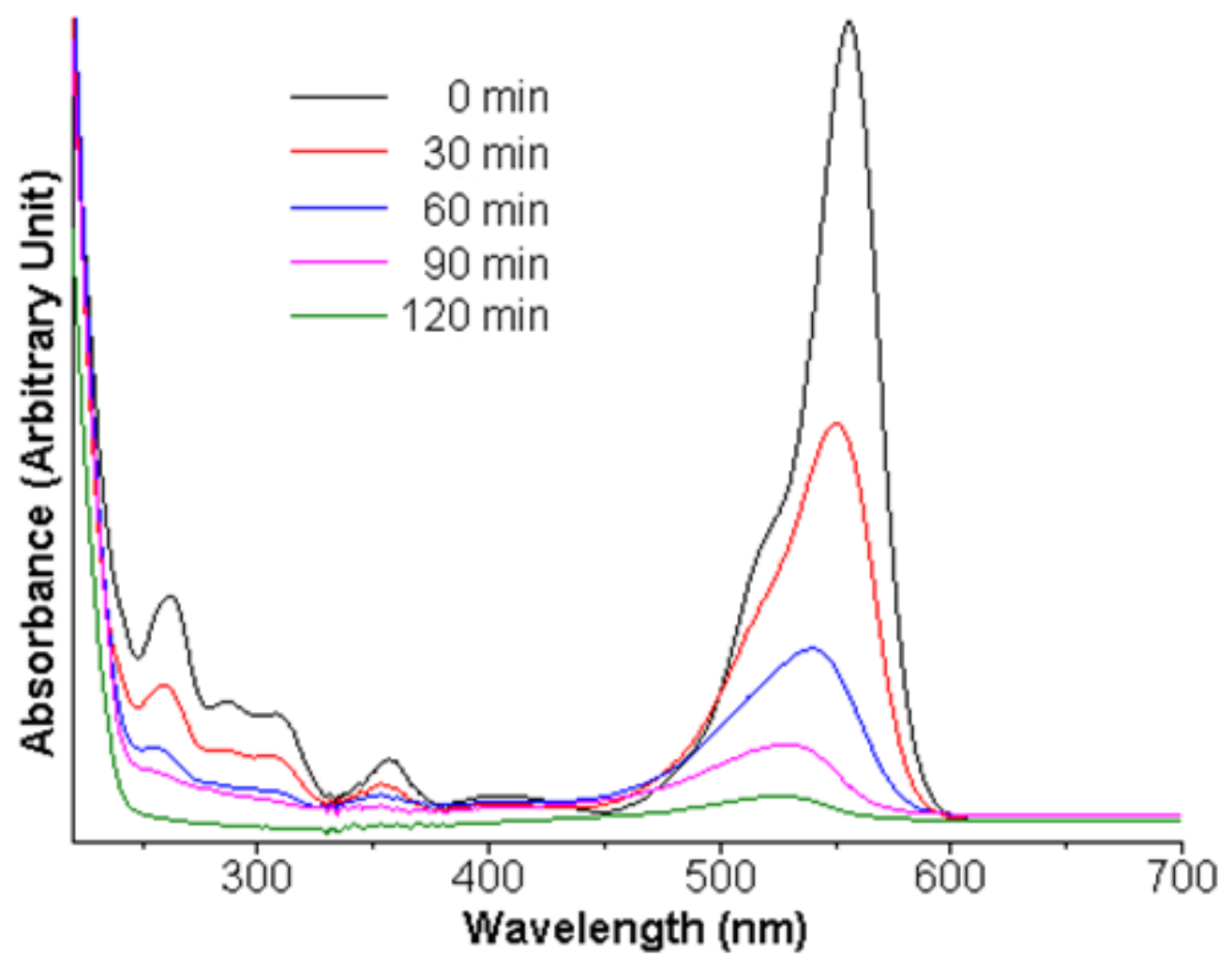

Figure 7

UV-visible absorption of RhB solutions photocatalyzed by $10 \% \mathrm{Pd} / \mathrm{Bi} 2 \mathrm{~W} 06$ nanocomposites under visible light irradiation within 120 min. 

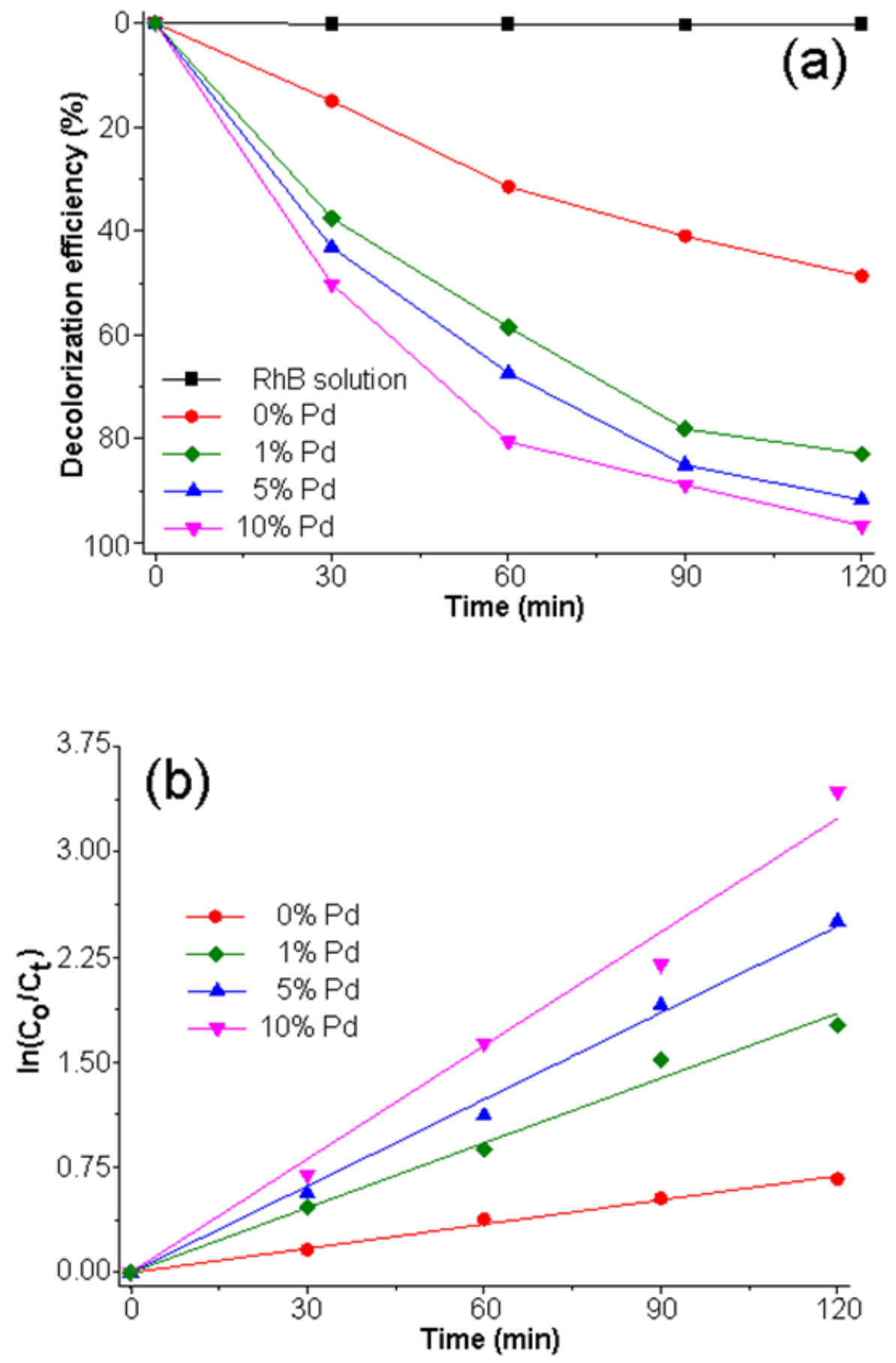

Figure 8

(a) Decolorization efficiency and (b) pseudo-first-order plot for photodegradation of RhB solutions over 0-10\% Pd/Bi2WO6 samples comparing with decolorization efficiency of RhB solution without a photocatalyst. 


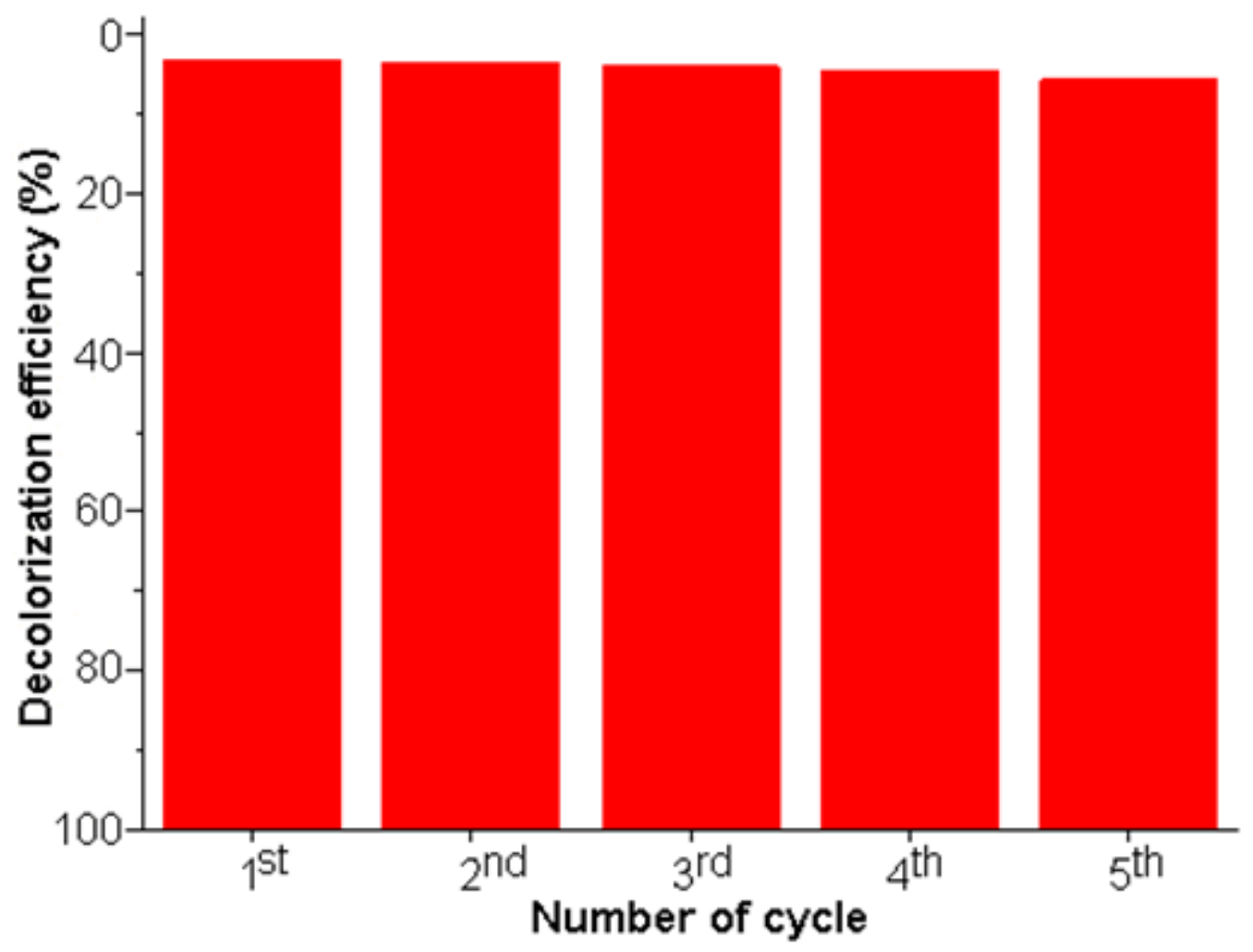

Figure 9

Photocatalysis of re-used 10\% Pd/Bi2WO6 nanocomposites for five recycles.

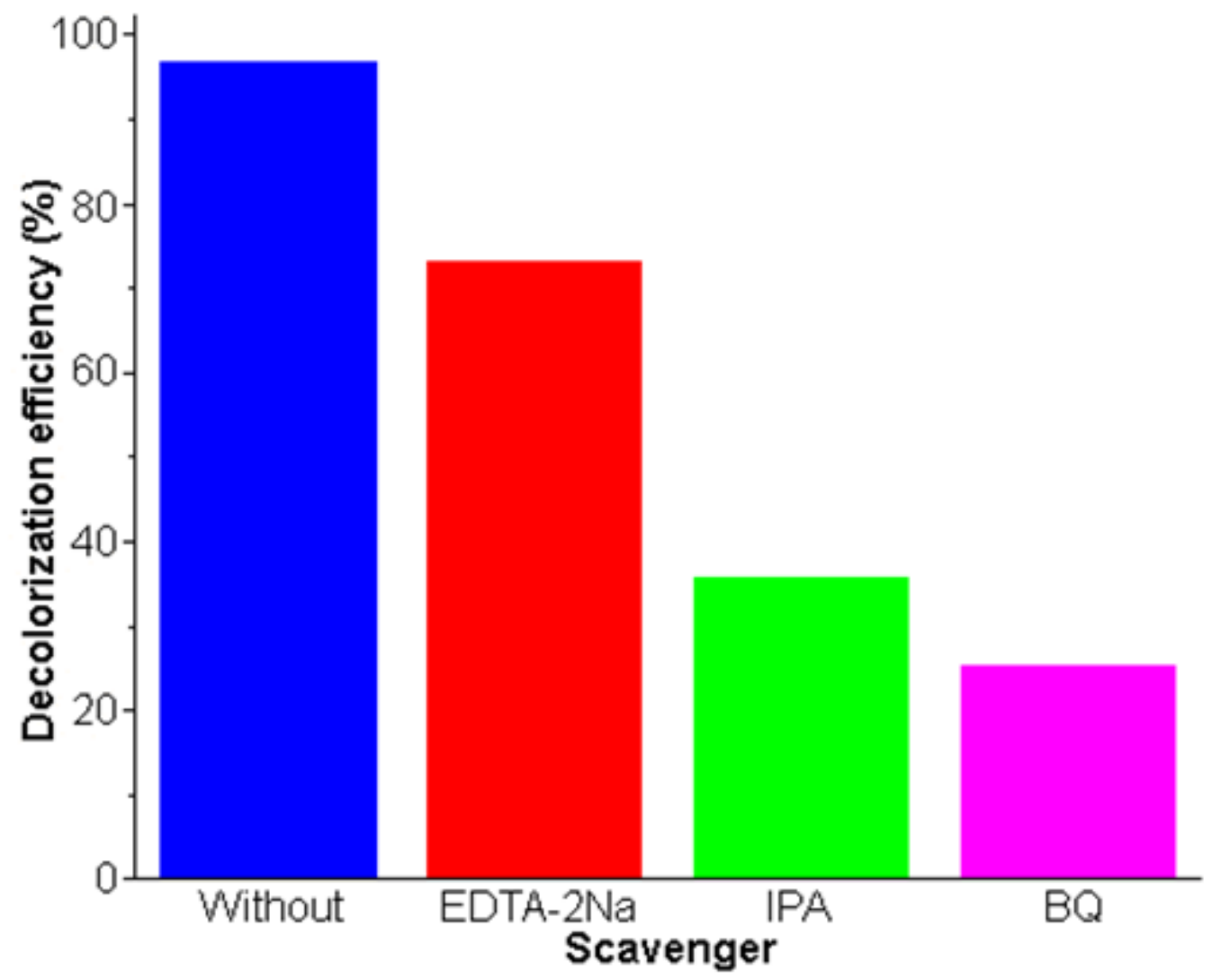


Figure 10

Photodegradation of RhB solutions containing different active scavengers comparing with that without a scavenger over $10 \% \mathrm{Pd} / \mathrm{Bi} 2 \mathrm{WO} 6$ nanocomposites.

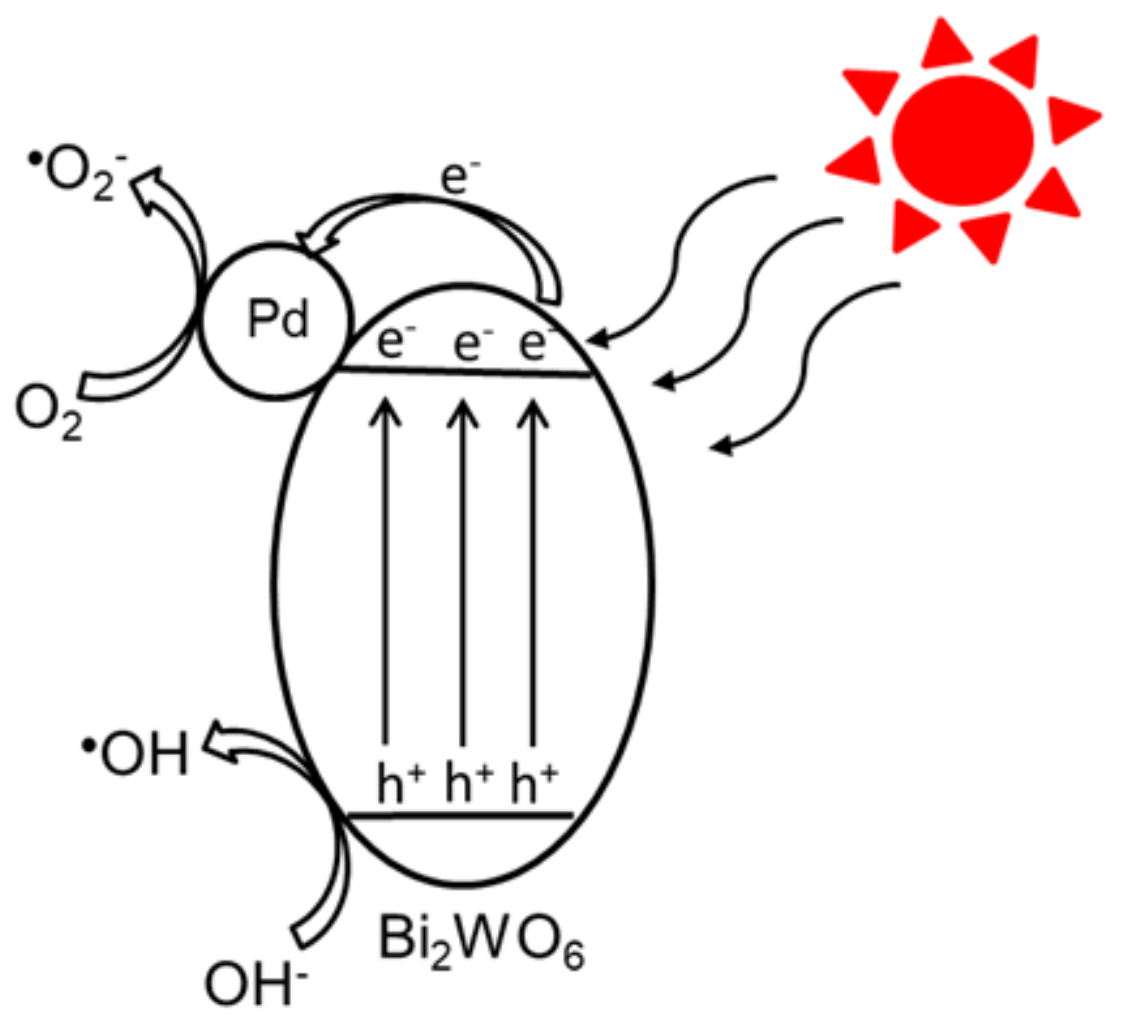

Figure 11

Schematic diagram for photocatalytic mechanism of Pd/Bi2WO6 nanocomposites. 